\title{
Dramatic response to sirolimus in lymphangioleiomyomatosis
}

\author{
Dmitry Rozenberg MD FRCPC, John Thenganatt MD FRCPC
}

\begin{abstract}
41-year-old woman presented with a one-year history of progresAsive dyspnea, early satiety and abdominal cramping. A clinical diagnosis of lymphangioleiomyomatosis (LAM) was made based on a confirmed right-sided chylous effusion (milky, exudative and triglyceride level of $52.6 \mathrm{mmol} / \mathrm{L}$ ) and characteristic cystic changes on a highresolution computed tomography scan of the chest (Figure 1). A large left-sided retroperitoneal lymphangioleiomyoma supported the diagnosis (Figure 2), with no renal angiomyolipoma or clinical evidence of tuberous sclerosis. She was started on sirolimus therapy, which resolved her dyspnea and abdominal symptoms within six months. Her forced expiratory volume in $1 \mathrm{~s}\left(\mathrm{FEV}_{1}\right)(1.6 \mathrm{~L})$ and FVC $(2.1 \mathrm{~L})$ had markedly improved during this time interval to $2.6 \mathrm{~L}$ and $4.2 \mathrm{~L}$, respectively. Her chest $\mathrm{x}$-ray demonstrated almost complete resolution of the right pleural effusion (Figure 3) and the lymphangioleiomyoma had also decreased in size (Figure 4). The patient remains clinically stable
\end{abstract}

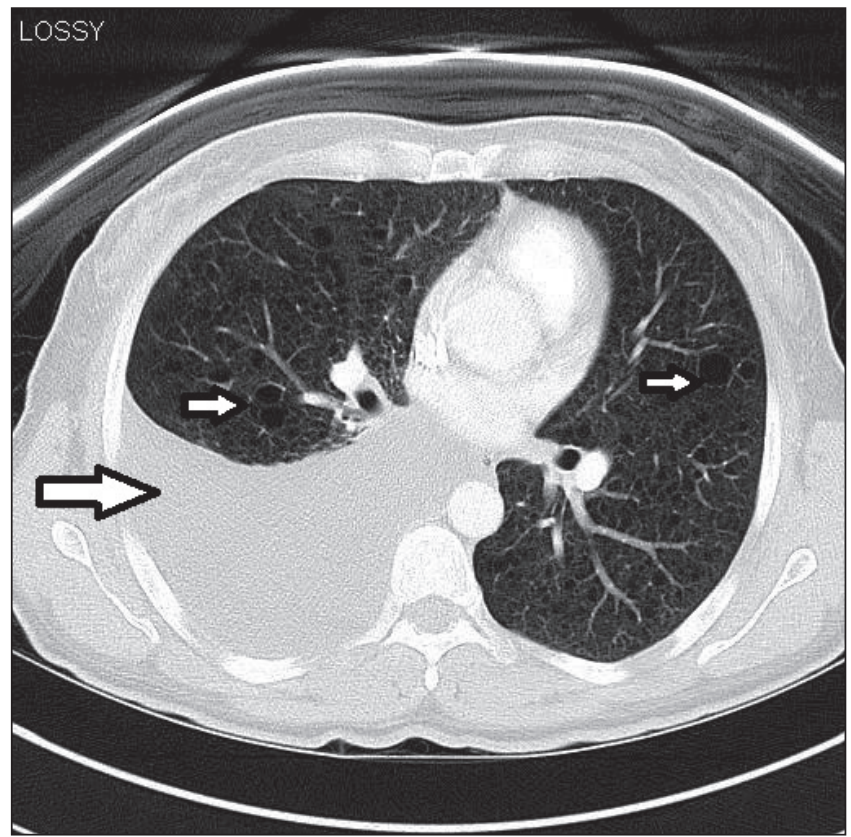

Figure 1) High-resolution computed tomography image demonstrating cystic changes (small arrows) with right-sided chylous effusion (large arrow) before sirolimus therapy on sirolimus with few side effects and her $\mathrm{FEV}_{1}$ and FVC on therapy at nine months increased to $3.3 \mathrm{~L}(96 \%)$ and $4.8 \mathrm{~L}$ (118\%), respectively. The present case is a dramatic example of a chylous pleural effusion and massive intra-abdominal lymphangioleiomyoma responding to sirolimus therapy.

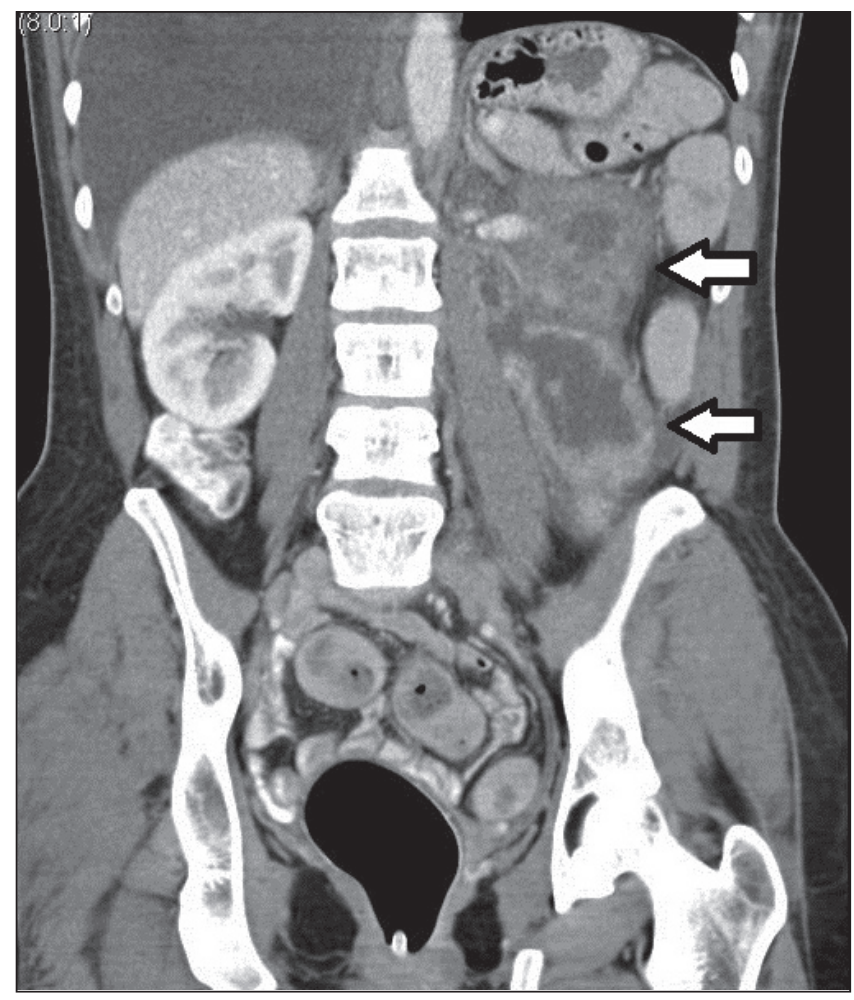

Figure 2) Contrast computed tomography image of retroperitoneal lymphangioleiomyoma (arrows) before therapy. The dimensions of the lymphangioleimyoma were: craniocaudal $16.5 \mathrm{~cm}$; anteroposterior $6.8 \mathrm{~cm}$; and transverse $8.7 \mathrm{~cm}$. This is a typical computed tomography image of a lymphangioleimyoma, which are commonly complex lymphatic masses with either thick or thin walls encompassing low-attenuation material consistent with chyle

Depatrment of Respirology, University of Toronto, Toronto General Hospital, Toronto, Ontario

Correspondence: Dr Dmitry Rozenberg, Depatrment of Respirology, Toronto General Hospital, 9N 965 - 585 University Avenue,

Toronto, Ontario M5G 2N2. Telephone 416-340-4591, fax 416-340-3109, e-mail dmitry.rozenberg@uhn.ca 


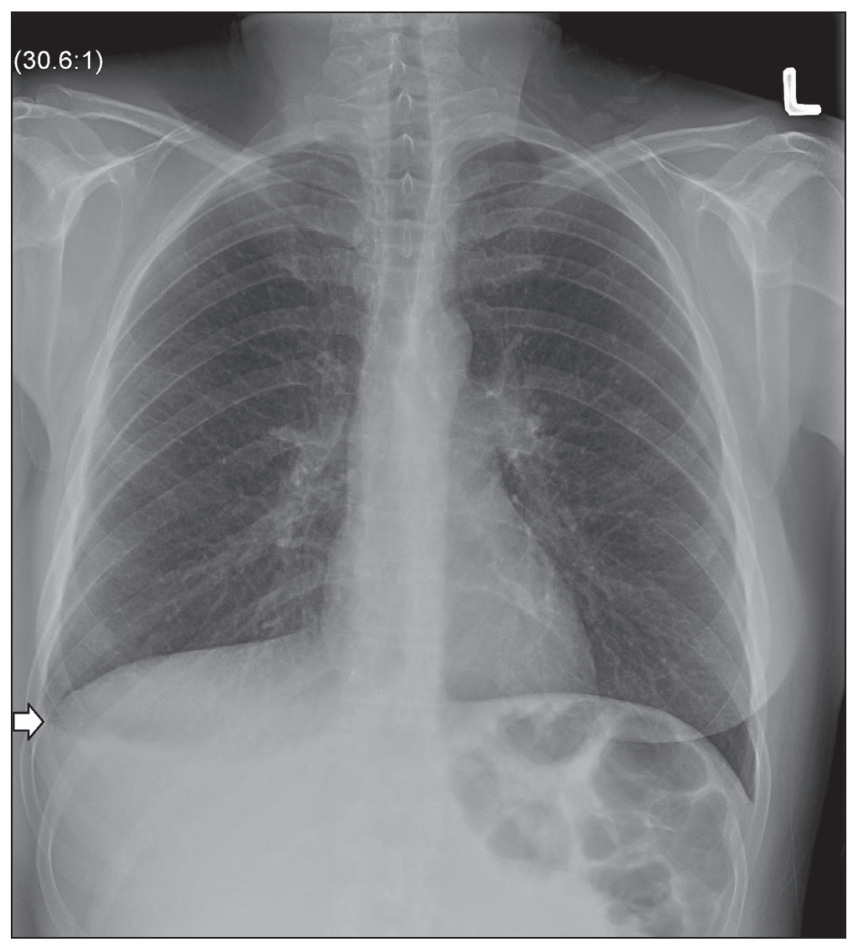

Figure 3) Chest $x$-ray demonstrating almost complete resolution of rightsided chylous effusion (arrow) at six months of sirolimus therapy

\section{KEY LEARNING POINTS}

- LAM is a rare progressive lung disease that affects women of child-bearing age.

- It is caused by proliferation of abnormal smooth-muscle-like cells and is characterized by cystic lung destruction, chylous effusions, lymphangioleiomyomas and angiomyolipomas.

- A clinical diagnosis of LAM can be made in patients who present with typical cystic changes on high-resolution computed tomography and angiomyolipomas, tuberous sclerosis or chylous effusion (1).

- Other considerations for multicystic lung disease include the following: emphysema, follicular bronchiolitis with or without lymphocytic interstitial pneumonitis, pulmonary Langerhans cell histiocytosis or Birt-Hogg Dubé syndrome.

- Before 2011, there were no proven treatments available for LAM; however, sirolimus has been shown to stabilize lung function, improve quality of life, reduce chylous effusions and decrease lymphangioleiomyomas $(2,3)$.

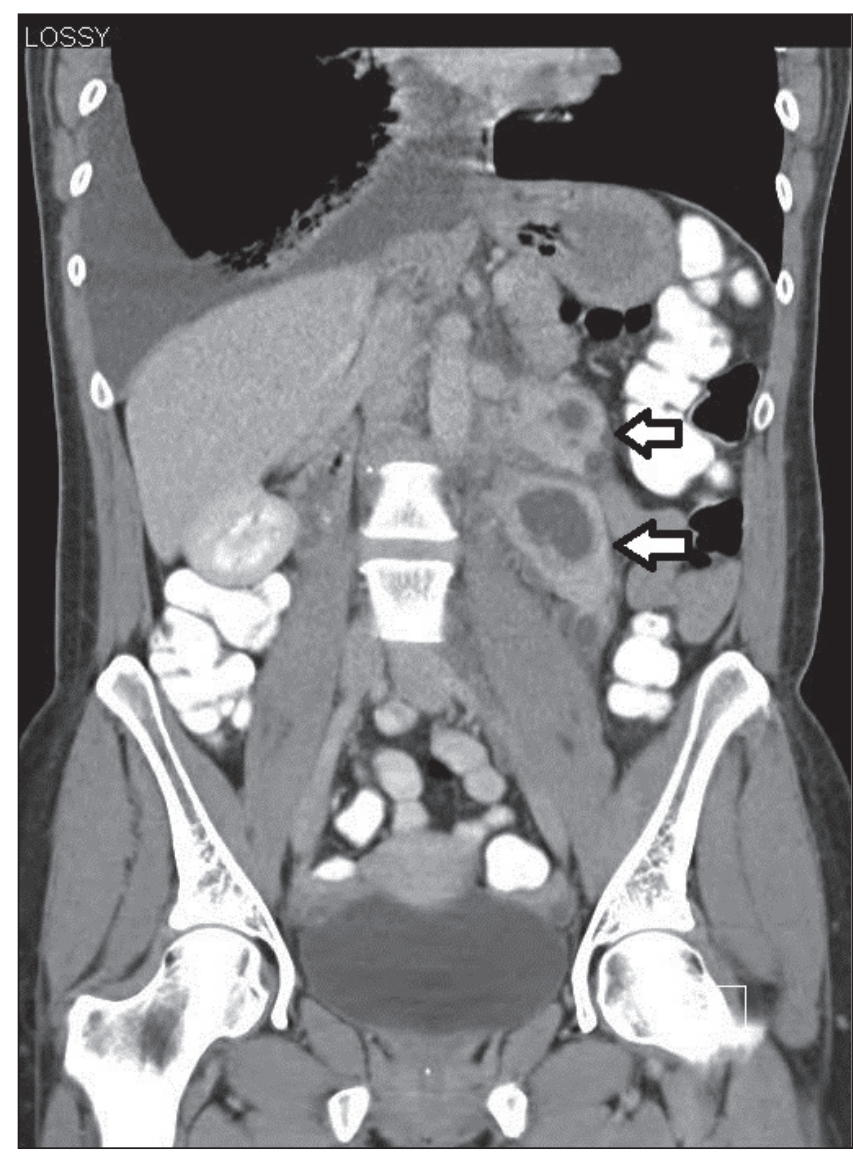

Figure 4) Repeat contrast computed tomography scan demonstrating a dramatic decrease in size of the lymphangioleiomyoma (arrows) after three months of therapy. The dimensions were: craniocaudal $10.5 \mathrm{~cm}$; anteroposterior $4.1 \mathrm{~cm}$; and transverse $4.4 \mathrm{~cm}$

\section{REFERENCES}

1. Johnson SR, Cordier JF, Lazor R, et al. European Respiratory Society guidelines for the diagnosis and management of lymphangioleiomyomatosis. Eur Respir J 2010;35:14-26.

2. Taveira-DaSilva AM, Hathaway O, Stylianou M, et al. Changes in lung function and chylous effusions in patients with lymphangioleiomyomatosis treated with sirolimus. Ann Intern Med 2011;154:797-805, W-292-3.

3. McCormack FX, Inoue Y, Moss J, et al. Efficacy and safety of sirolimus in lymphangioleiomyomatosis. N Engl J Med 2011;364:1595-606. 


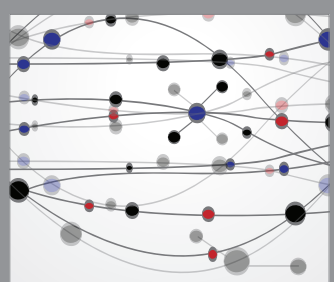

The Scientific World Journal
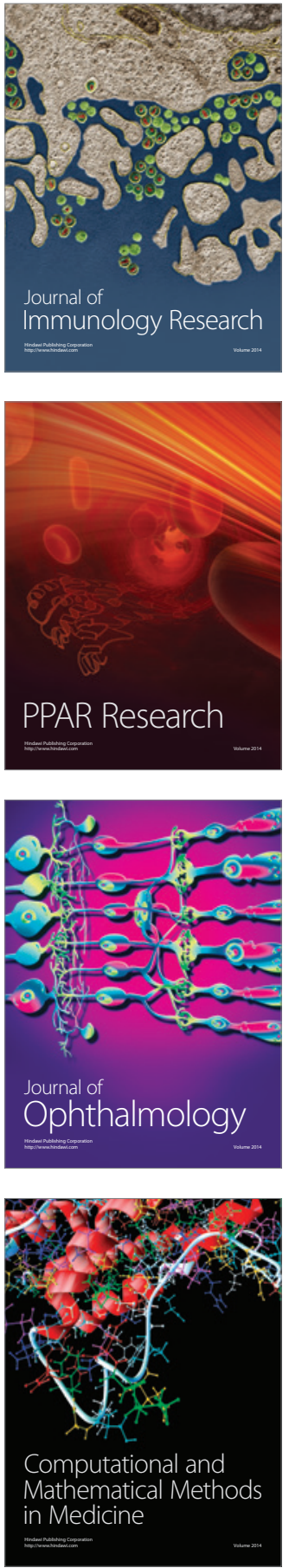

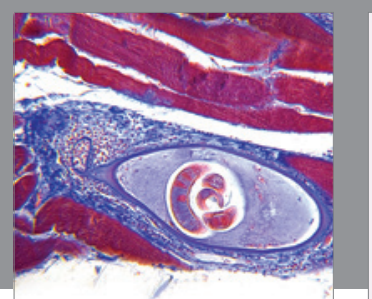

Gastroenterology Research and Practice

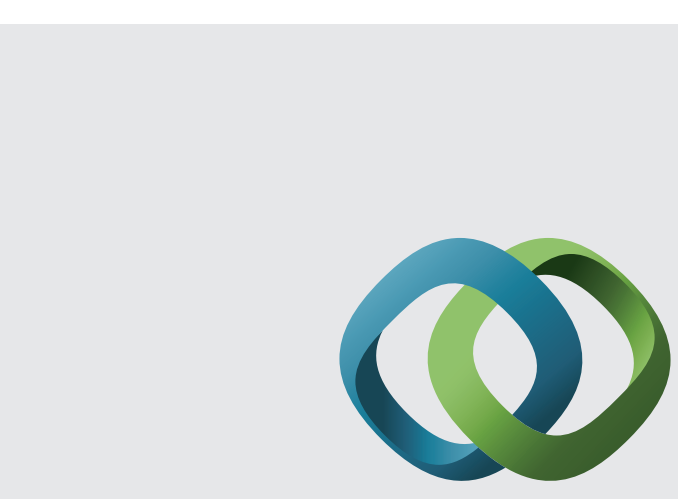

\section{Hindawi}

Submit your manuscripts at

http://www.hindawi.com
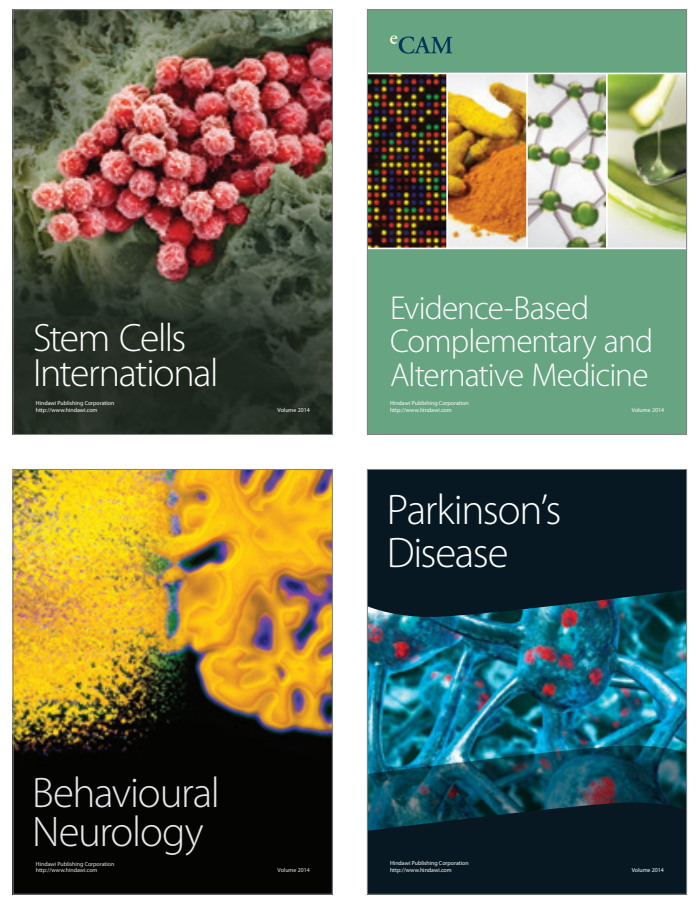
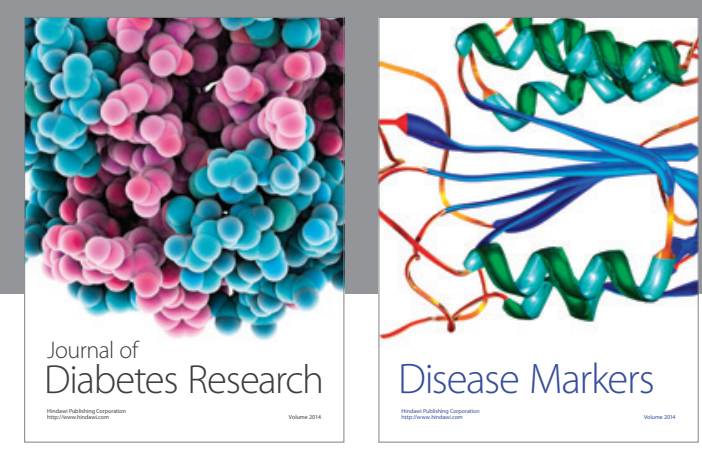

Disease Markers
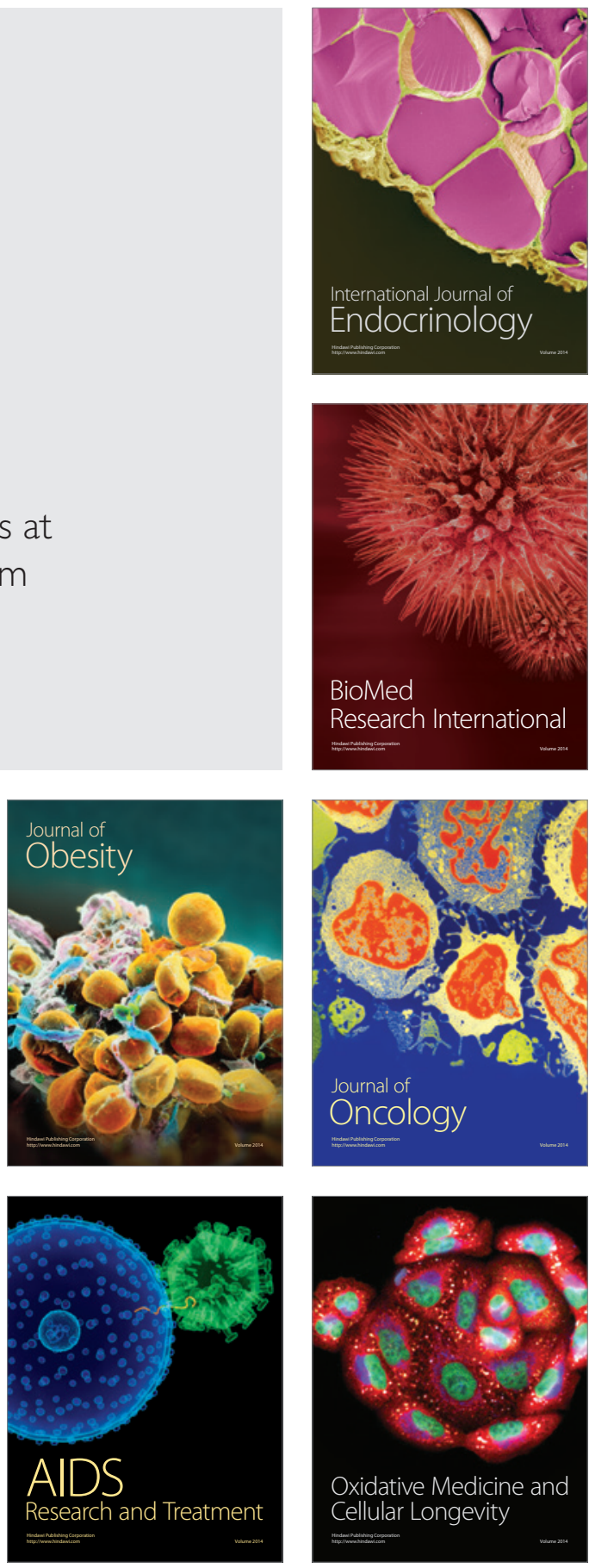